\title{
Shortwave surface radiation network for observing small-scale cloud inhomogeneity fields
}

\author{
Bomidi Lakshmi Madhavan $^{1}$, John Kalisch ${ }^{2, a}$, and Andreas Macke ${ }^{1}$ \\ ${ }^{1}$ Leibniz-Institute for Tropospheric Research (TROPOS), Permoserstraße 15, 04318 Leipzig, Germany \\ ${ }^{2}$ Department of Energy and Semiconductor Research, Carl von Ossietzky University Oldenburg, Oldenburg, Germany \\ ${ }^{a}$ now at: WRD Wobben Research and Development GmbH, Aurich, Germany \\ Correspondence to: Bomidi Lakshmi Madhavan (madhavan.bomidi@tropos.de)
}

Received: 24 September 2014 - Published in Atmos. Meas. Tech. Discuss.: 9 March 2015

Revised: 13 March 2016 - Accepted: 14 March 2016 - Published: 18 March 2016

\begin{abstract}
As part of the High Definition Clouds and Precipitation for advancing Climate Prediction Observational Prototype Experiment (HOPE), a high-density network of 99 silicon photodiode pyranometers was set up around Jülich $(10 \mathrm{~km} \times 12 \mathrm{~km}$ area) from April to July 2013 to capture the small-scale variability of cloud-induced radiation fields at the surface. In this paper, we provide the details of this unique setup of the pyranometer network, data processing, quality control, and uncertainty assessment under variable conditions. Some exemplary days with clear, broken cloudy, and overcast skies were explored to assess the spatiotemporal observations from the network along with other collocated radiation and sky imager measurements available during the HOPE period.
\end{abstract}

\section{Introduction}

Solar radiation reaching the Earth's surface is significantly modulated by interaction with clouds that are highly variable in space and time. These interactions and other interlinked processes contribute to the redistribution of global radiative energy and hydrological balances in the Earth's atmosphere that govern the climate system (Stephens, 2005). One of the most critical and less understood aspects of uncertainty in climate simulations is the role of cloud-radiative processes and their interplay with precipitation (Boucher et al., 2013). Clouds scatter and absorb the incoming solar radiation, reducing the shortwave radiation reaching the Earth's surface. A particularly sensitive component of incoming solar radiation that can trace the cloud inhomogeneity fields at the surface is the "global horizontal irradiance", also referred to as "surface insolation". This is the total shortwave irradiance from the hemisphere above the horizontal plane surface and includes both the direct and diffuse components of the incident radiation (WMO, 2008). Apart from radiative research interests, the spatiotemporal measurements of surface insolation are of interest to solar power plants (Robles Gil, 2007), crop yield prediction, and water resource management (Roebeling et al., 2004), as well as for improving numerical weather prediction models (van den Hurk et al., 1997).

Various ground-based radiation networks, namely the Canadian radiation network operated by the Meteorological Service of Canada (Barker et al., 1998), the World Meteorological Organization's Baseline Surface Radiation Network (BSRN) (Ohmura et al., 1998), the Atmospheric Radiation Measurement (ARM) Program (Michalsky et al., 1999), and the National Oceanic and Atmospheric Administration's Surface Radiation (SURFRAD) network (Augustine et al., 2000), were available for the past decades to quantify the Earth's radiation budget, validate satellite-derived products and climate model simulations, and detect climate change signals in long-term records. However, the large uncertainties in the surface radiation budget are still less quantified than the top-of-atmosphere (TOA) budget (Wild et al., 2013). To complement these surface radiation networks, various methods were developed to derive shortwave surface irradiance using both polar-orbiting and geostationary satellite observations (e.g., Schmetz, 1989; Pinker et al., 1995). Surface solar irradiances derived from the cloud properties retrieved from Meteosat Second Generation Spinning Enhanced Visible and Infrared Imager (MSG SEVIRI) showed that the 
retrievals are comparable to those measured with first-class ground-based instruments by $5 \%$ of their daily means in summer, while the accuracy reduced significantly by a factor of 3-4 in winter owing to low solar elevation angles over the Netherlands (Deneke et al., 2008). In addition, these existing meteorological satellite imagers use 1-D radiative transfer with an assumption that clouds are plane parallel and horizontally homogeneous to retrieve the cloud properties. Such simplified representation of spatially inhomogeneous clouds in radiative transfer models leads to systematic errors when calculating broadband radiative fluxes (Scheirer and Macke, 2003). Further, the 3-D cloud radiative effects also leads to significant biases in satellite-derived surface irradiances that are sensitive to viewing and solar geometry (Kato et al., 2006). In most cases, clouds with significant smallscale variability, horizontal photon transport, and radiative smoothing tend to dissociate variations in TOA reflectance with transmittance from surface measurements (Barker and Li, 1997; Deneke et al., 2009). Small clouds and their subpixel variability often increase uncertainties on spatial scales at or below the resolution of satellite images (Koren et al., 2008). Understanding such small-scale variability will help to assess the accuracy that can be attained in validation studies when comparing point measurements with satellite area estimates (linked to pixel size) or model cell results and comparing satellite area estimates with model cell results. Thus, there is a definite need for dense surface radiation networks for resolving cloud-induced variability at sub-scale satellite pixel resolution.

Clouds are simulated poorly in the existing global climate models because of their coarse grid resolution. The processes important for cloud formation happen at much smaller scales, and it is often difficult to represent clouds and these small-scale processes with the mean grid-box properties. With a view towards improving the cloud-precipitation processes in climate model simulations, the "High Definition Clouds and Precipitation for advancing Climate Prediction" $\left(\mathrm{HD}(\mathrm{CP})^{2}\right)$ project (http://hdcp2.eu/) was funded by the Federal Ministry of Education and Research (BMBF), Germany. In order to access the 3-D structure of clouds at $\mathrm{HD}(\mathrm{CP})^{2}$ model resolution, the $\mathrm{HD}(\mathrm{CP})^{2}$ Observational Prototype Experiment (HOPE) was designed to measure the sub-gridscale variability of dynamical, thermodynamical, and cloud microphysical properties. This HOPE measurement campaign was conducted around the super-site JOYCE (Jülich ObservatorY for Cloud Evolution) with an aim to provide data sets for critical model evaluation at the scales of model simulation. Within the observational sub-module $\mathrm{O} 4$, the measurements were organized into five work packages focused on land-surface exchange processes (WP1), planetary boundary layer studies (WP2), aerosol and cloud microphysics (WP3), cloud morphology (WP4), and radiative closure studies (WP5). In WP5, our focus was to probe the spatiotemporal variability of cloud-induced radiation fields at the surface with a resolution comparable to or even bet- ter than $\mathrm{HD}(\mathrm{CP})^{2}$ model grid box. See Macke and HOPETeam (2016) for an overview on various observational findings from the HOPE campaign.

In this context, the present paper is aimed at providing an overview on our experimental contribution towards setting up of the surface radiation network with high spatial and temporal resolution during HOPE. The outline of the paper is as follows: in Sect. 2, details about instrumentation and experimental setup are described. Data processing, quality control, and uncertainty assessment are given in Sect. 3. In Sect. 4, we mainly focus on exploring some of the days with a clear, broken cloudy, and overcast skies to assess the variability in the spatiotemporal observations along with other collocated radiation measurements and sky imagers. Finally, conclusions and a brief outlook are presented in Sect. 5 .

\section{Instrumentation, experimental setup, and data availability}

\subsection{Pyranometer Network (PyranoNET)}

In order to observe the small-scale variability of cloudinduced shortwave surface radiation fields at a high spatiotemporal resolution, we have developed a set of $100 \mathrm{au}-$ tonomous pyranometer stations equipped with meteorological sensors (relative humidity (RH) and air temperature) for the HOPE campaign. Each station is built with the following main components.

i. An EKO silicon photodiode pyranometer (model: ML020VM) for measuring the shortwave global irradiance $\left(G\right.$ in $\mathrm{W} \mathrm{m}^{-2}$ ) in the spectral range $0.3-1.1 \mu \mathrm{m}$. The limited spectral range is a well-known constraint of this type of pyranometer due to the narrow spectral response of the photodiode. In comparison to thermopile pyranometers, silicon photodiode sensors have a superior response time enabling a sampling frequency of $10 \mathrm{~Hz}$, which allows it to follow the rapid changes in the sky. Further specification details are listed in Table 1.

ii. A micromodule (model: Driesen+Kern DKRF 4001-P) combines air temperature and RH sensors for meteorological measurements. While the temperature sensor has a measurement range from 253.15 to $353.15 \mathrm{~K}$ (i.e., -20 to $\left.+80^{\circ} \mathrm{C}\right), \mathrm{RH}$ sensor measurements range from 0 to $100 \%$. The accuracy of the temperature measurement is $\pm 1.5 \mathrm{~K}$ at $233.15 \mathrm{~K}$, decreases linearly to $\pm 0.5 \mathrm{~K}$ at $273.15 \mathrm{~K}$ and remains stable up to $313.15 \mathrm{~K}$, and again increases linearly to $\pm 1.5 \mathrm{~K}$ at $353.15 \mathrm{~K}$. Similarly, the accuracy of RH measurement is $\pm 3.5 \%$ at $0 \% \mathrm{RH}$, decreasing linearly to $\pm 2 \%$ at $10 \% \mathrm{RH}$ to remain stable until $90 \%$, thereafter increasing linearly and reaching $\pm 3.5 \%$ at $100 \% \mathrm{RH}$.

iii. A compact GPS (Global Positioning System) receiver module (model: Fastrax UP501) with embedded GPS 
Table 1. Specifications of various components of the measurement system.

\begin{tabular}{|c|c|}
\hline $\begin{array}{l}\text { (a) Pyranometer sensor: EKO ML-020VM } \\
\text { Parameters }\end{array}$ & $\begin{array}{l}\text { (source: http://eko-eu.com/) } \\
\text { ML-020VM characteristics }\end{array}$ \\
\hline Response time (time to reach $95 \%$ response) & $10 \mathrm{~ms}$ \\
\hline Zero offset - thermal radiation $\left(200 \mathrm{~W} \mathrm{~m}^{-2}\right)$ & $0 \mathrm{~W} \mathrm{~m}^{-2}$ \\
\hline Zero offset - temperature change $\left(5 \mathrm{Kh}^{-1}\right)$ & $0 \mathrm{~W} \mathrm{~m}^{-2}$ \\
\hline Non-stability ${ }^{\mathrm{a}}$ & $\pm 2 \%$ \\
\hline Nonlinearity ${ }^{b}$ & $<0.2 \%$ \\
\hline Directional response $^{\mathrm{c}}$ (at $30 / 60 / 80^{\circ}$ ) & $1 / 1.5 / 17 \%$ \\
\hline Tilt response (at $1000 \mathrm{~W} \mathrm{~m}^{-2}$ ) & $0 \%$ \\
\hline Temperature response $\mathrm{d}^{\mathrm{d}}$ & $\pm 0.5 \%$ \\
\hline Spectral error (during the day) & $\pm 2-5 \%$ \\
\hline (b) ADC data logger: LPC2141/42/44/46/48 & (source: https://www.sparkfun.com) \\
\hline Parameters & ADC static characteristics \\
\hline Analog power supply output & $3.3 \mathrm{~V}$ \\
\hline Temperature range & -40 to $+85^{\circ} \mathrm{C}$ \\
\hline Differential linearity error (resolution) & $\pm 1 \mathrm{LSB}^{\mathrm{e}}$ \\
\hline Gain error ${ }^{f}$ & $\pm 0.5 \%$ \\
\hline (c) Amplifier: INA 333 & (source: http://www.ti.com/product/INA333) \\
\hline Parameters & Characteristics \\
\hline Operational temperature range & -40 to $+150^{\circ} \mathrm{C}$ \\
\hline Power supply voltage range & $1.8-5.5 \mathrm{~V}$ \\
\hline Range of gain & 1 to 1000 \\
\hline Gain error & $\pm 0.3 \%($ Gain $=300)$ \\
\hline
\end{tabular}

a $\%$ change in responsivity per year.

$\mathrm{b} \%$ deviation from responsivity at $1000 \mathrm{Wm}^{-2}$ due to change in irradiance.

${ }^{c}$ Directional response of $17 \%$ at $80^{\circ}$ indicate that the sensitivity drops to 0.83 at $80^{\circ}$ polar angle of incidence.

$\mathrm{d} \%$ deviation due to change in ambient temperature from -10 to $+50^{\circ} \mathrm{C}$.

${ }^{\mathrm{e}}$ LSB is the least significant bit representing the smallest level that an ADC can convert.

${ }^{\mathrm{f}}$ Relative difference in \% between the straight line fitting the actual transfer curve after removing offset error and the straight line which fits the ideal transfer curve.

antenna for reliable timing and positioning information. The output data are in accordance with NMEA (National Marine Electronics Association) 0183 protocol.

iv. A micro-controller ARM7-based data logger board (model: Sparkfun Electronics Logomatic v2) with a built-in micro-SD socket is used to save data onto an SD card.

v. A power supply unit (i.e., 6V/19 Ah Zinc carbon VARTA 4R25-2 battery) with a lifetime of 10 days enables continuous usage.

A pyranometer station in the field and the schematic data flow from pyranometer through logger to memory storage device is shown in Fig. 1. The data logger software has been modified to enable simultaneous recording of data from the GPS, pyranometer, temperature, and RH modules. The logger's internal real-time clock is synchronized with the GPS time frequently and all the data are stored on a micro-SD card ( $\sim 2 \mathrm{~GB})$. The voltage signal detected by each pyranometer sensor ranges from 0 to $10 \mathrm{mV}\left(\sim 0\right.$ to $\left.1400 \mathrm{~W} \mathrm{~m}^{-2}\right)$ and an amplifier (INA333) enhances the signal by a factor of 300 to convert the signal in the range of $0-3 \mathrm{~V}$. Note that the amplification of pyranometer signal is independent of the fading battery voltage because the stabilized output voltage (3.3 V) was used from the data logger board. If the battery voltage is too weak, then the whole logger board does not work anymore. In case of temperature and RH sensors, their respective measurement ranges are related with the output voltage from 0 to $2.5 \mathrm{~V}$. These voltage signals are scaled to 10 bit counts ranging from 0 to 1023 and stored on the memory card.

\subsection{HOPE campaign and data availability}

During the HOPE campaign, we have set up 99 pyranometer stations covering the spatial domain of $50.85-50.95^{\circ} \mathrm{N}$ and $6.36-6.50^{\circ} \mathrm{E}(\sim 10 \mathrm{~km} \times 12 \mathrm{~km}$ area) around Jülich (mostly in open farm fields). Each measurement system was placed on a mounting rod, which is approximately $1.8 \mathrm{~m}$ high above the ground, and provides the measurements (in 10 bit counts) corresponding to the downward shortwave global irradiance, air temperature, and $\mathrm{RH}$ at $10 \mathrm{~Hz}$ frequency while the GPS 


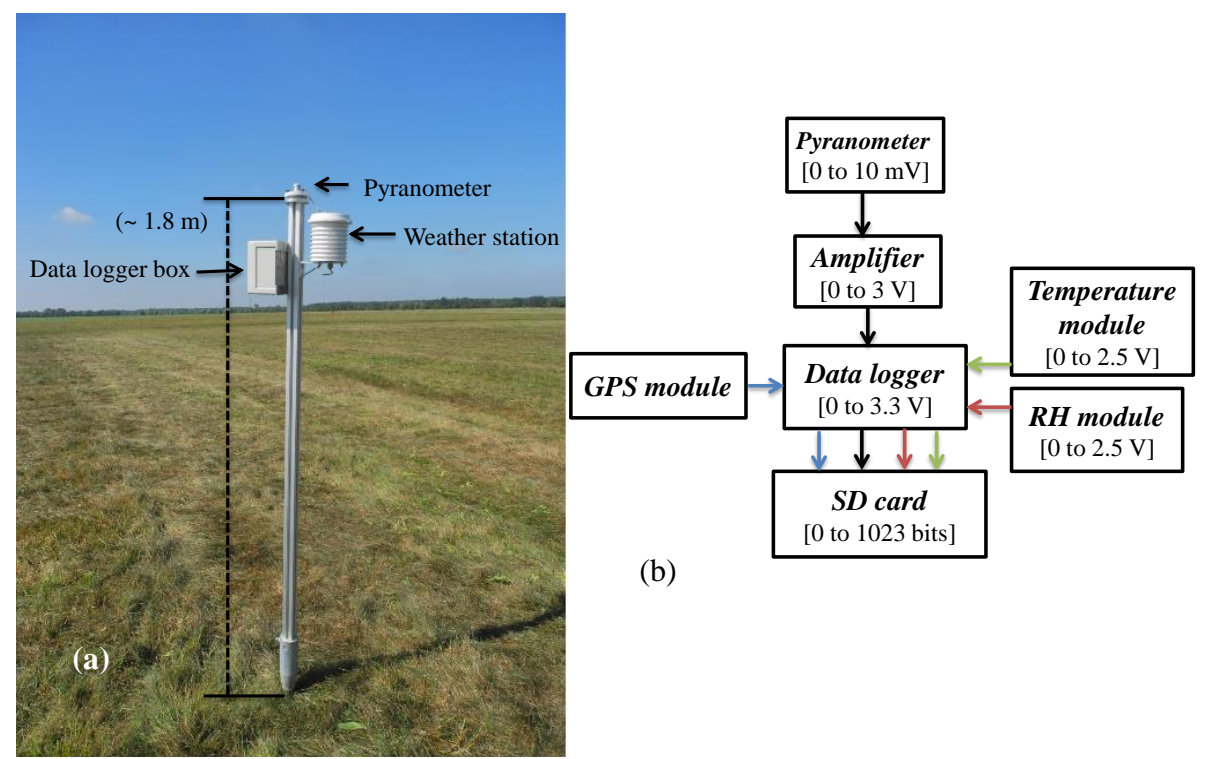

Figure 1. (a) Picture of a pyranometer station in the field and (b) the flow diagram for data recording.

information (latitude, longitude, time, etc.) is obtained at $1 \mathrm{~s}$ resolution. The spatial setup of pyranometer stations during the HOPE campaign is shown in Fig. 2. This network was continuously operational from 2 April to 24 July 2013 to capture the small-scale variability of cloud inhomogeneity fields at the surface.

Sites of the Research Center Jülich (FZJ) and the Karlsruhe Institute of Technology Hambach (KIT1, KIT2) were equipped with thermopile pyranometers, while the site of the Leipzig Aerosol and Cloud Research Observations System (LACROS) had an operational sky imager. These collocated sites with supplementary measurements are also shown in Fig. 2. With respect to the thermopile pyranometers at FZJ, KIT1, and KIT2, the nearest pyranometers from the network are spatially apart by $29.5,227.5$, and $343.5 \mathrm{~m}$. Global horizontal irradiance measurements from thermopile pyranometers at FZJ were obtained as $1 \mathrm{~min}$ averages while those from KIT1 and KIT2 are available at $1 \mathrm{~Hz}$ resolution.

\section{Data processing, quality control, and uncertainty estimation}

\subsection{Data processing}

The EKO ML-020VM silicon photodiode pyranometers were calibrated against a reference ML-020VM sensor using an indoor solar simulator. This reference sensor was initially calibrated against another reference thermopile pyranometer. In our case, the sensor sensitivity is a single number determined under standard conditions with a specific spectrum that converts the narrowband response to an equivalent broadband response. The ML-020VM pyranome-

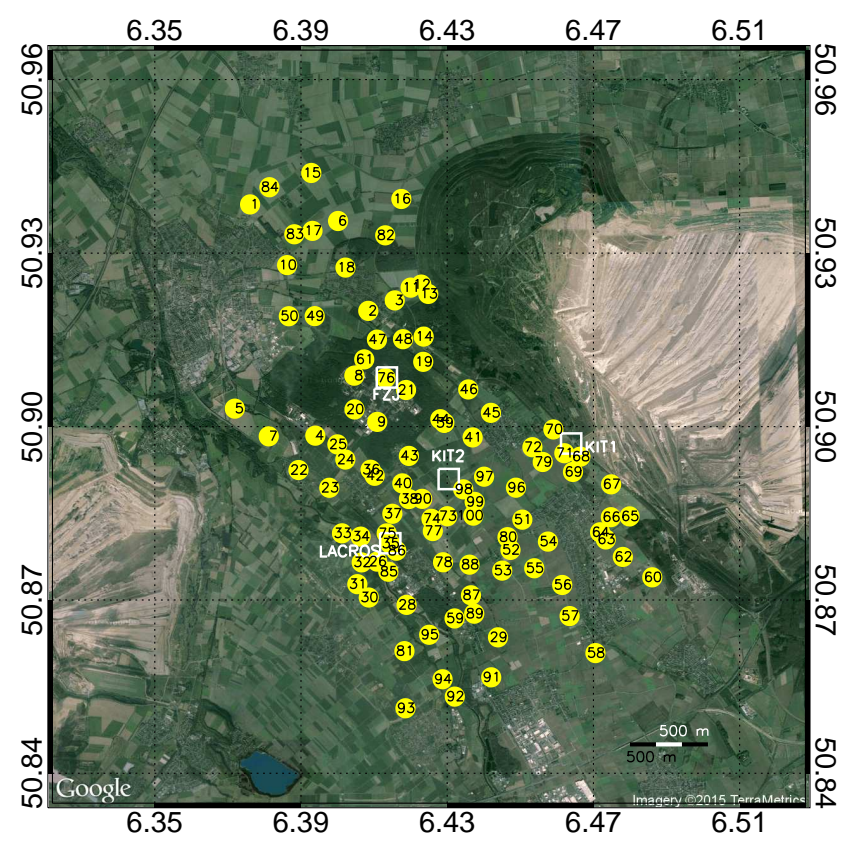

Figure 2. Spatial distribution of pyranometer network during HOPE campaign. Each yellow circle represents a pyranometer station with a unique station identification number. Collocated sites with additional measurements from thermopile pyranometers (at FZJ, KIT1, KIT2) and a sky imager (at LACROS) are marked in open white squares. (Source for background image: Google).

ter sensors have calibration factors that range from 6.3 to $7.7 \mu \mathrm{VW}^{-1} \mathrm{~m}^{2}$ (provided by the manufacturer).

The raw data stored in the form of 10 bit counts are converted to global horizontal irradiance $\left(G\right.$ in $\left.\mathrm{W} \mathrm{m}^{-2}\right)$, ambient air temperature ( $T_{\mathrm{a}}$ in $\mathrm{K}$ ), and $\mathrm{RH}$ (in \%) using the following 
equations:

$$
\begin{aligned}
& G=\left[\left(N_{\text {counts }} \cdot \frac{3.3}{1023}\right) \cdot\left(\frac{1}{300}\right)\right] \cdot \frac{1}{K_{\mathrm{c}}}, \\
& T_{\mathrm{a}}=\left[\left(N_{\text {counts }} \cdot \frac{3.3}{1023}\right) \cdot\left(\frac{100}{2.5}\right)-20\right]+273.15, \\
& \mathrm{RH}=\left[\left(N_{\text {counts }} \cdot \frac{3.3}{1023}\right) \cdot\left(\frac{1}{2.5}\right)\right] \cdot 100 .
\end{aligned}
$$

Here $N_{\text {counts }}$ corresponds to the respective sensor data in 10 bit counts and $K_{\mathrm{c}}$ denotes the calibration factor (in $\mathrm{VW}^{-1} \mathrm{~m}^{2}$ ) of a pyranometer sensor. Since our GPS did not provide sub-second information, both the pyranometer and meteorological measurements are averaged along $1 \mathrm{~s}$ time steps of the GPS. Additional information such as latitude, longitude, day, and time from the GPS was used to compute the solar zenith and azimuth angles as described in Liou (2002).

Atmospheric transmittance characterizes the fraction of radiation that passes through the column atmosphere under variable sky conditions at different solar zenith angles $\left(\theta_{0}\right)$. As this is derived from the global irradiance measurements by normalizing with a fixed value of extraterrestrial irradiance at the TOA corrected for geometrical factors, we also refer as global transmittance $(T)$. While the observed transmittance is sensitive to aerosols and cloud optical thickness, information on cloud thermodynamic phase and cloud droplet effective radius is outside the spectral range of our silicon photodiode pyranometer.

We convolute the standard solar spectrum of Gueymard (2004) with the EKO silicon photodiode spectral sensitivity (see Fig. 3) and then integrate the weighted EKO solar spectrum over the range of sensitivity to calculate the sensorspecific extraterrestrial irradiance $\left(S_{0}^{\prime}\right)$ using the following equation:

$$
S_{0}^{\prime}=\int_{\lambda_{1}}^{\lambda_{2}} \phi(\lambda) \cdot \eta(\lambda) \mathrm{d} \lambda,
$$

where $\lambda_{1}$ and $\lambda_{2}$ are the lower and upper spectral limits (in $\mu \mathrm{m}$ ), $\lambda$ is the wavelength (in $\mu \mathrm{m}$ ), $\phi$ is the extraterrestrial solar spectrum (in $\mathrm{W} \mathrm{m}^{-2} \mu^{-1}$ ) at a Sun-Earth distance of $1 \mathrm{AU}$ (or astronomical units), and $\eta$ denotes the spectral sensitivity of the EKO silicon photodiode sensor. Since the EKO pyranometers used in this study were calibrated to the full solar spectrum and not to the spectral range of the sensor, we use the climate significant total solar irradiance value of $1360.8 \pm 0.5 \mathrm{~W} \mathrm{~m}^{-2}$ at the TOA (Kopp and Lean, 2011) for deriving the global transmittance $(T)$ as given below:

$$
T=\frac{G^{\prime}}{\left[S_{0}^{\prime} \cdot\left(\frac{r}{r_{0}}\right)^{2}\right] \cdot \cos \theta_{0}}
$$

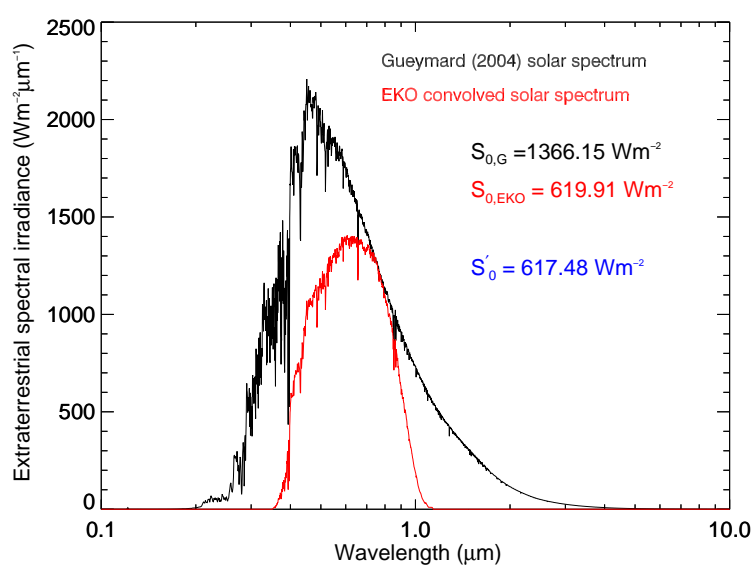

Figure 3. Extraterrestrial solar spectrum of Gueymard (2004) weighted by the spectral sensitivity of the EKO ML-020VM silicon photodiode sensor. Extraterrestrial irradiance at the TOA for Gueymard (2004) solar spectrum $\left(S_{0, G}\right)$ and that of EKO photodiode sensor $\left(S_{0, \text { EKO }}\right)$ were obtained as 1366.15 and $619.91 \mathrm{~W} \mathrm{~m}^{-2}$, respectively. Assuming the climate significant total solar irradiance value of $1360.8 \mathrm{~W} \mathrm{~m}^{-2}$ at the TOA (Kopp and Lean, 2011), the scaled EKO sensor-specific extraterrestrial irradiance $\left(S_{0}^{\prime}\right)$ was obtained as $617.48 \mathrm{~W} \mathrm{~m}^{-2}$.

Here $S_{0}^{\prime}\left(=617.48 \mathrm{~W} \mathrm{~m}^{-2}\right)$ is the sensor-specific extraterrestrial irradiance, $G^{\prime}\left(=\left(\frac{617.48}{1360.8}\right) \cdot G\right)$ is the scaled global horizontal irradiance in the spectral sensitivity range of the sensor, $r$ is the actual Sun-Earth distance (in AU), and $r_{0}$ is the mean Sun-Earth distance $(=1.0 \mathrm{AU})$. If there is no atmosphere, then the global transmittance will be unity.

\subsection{Quality control}

Global irradiance measurements from each pyranometer station may be influenced by various operational sources of uncertainty, namely horizontal misalignment of the sensor leveling plate, cleanliness of glass dome, short-time resting of birds or insects, water droplets (during rain, fog, or dew) on the glass dome, instrument malfunctioning, and shadowing due to close by structures (i.e., obstructions to free the horizon). A spirit (or bubble) level was available on the leveling plate, which mounts the pyranometer sensor. The screws of the leveling plate were adjusted on the mounting rod such that the bubble in the spirit level is always enclosed within the marked circle for perfect horizontal alignment (see Fig. S1 in the Supplement). During the campaign period, batteries were replaced every week and a record of the physical information, such as (i) cleanliness of the pyranometer glass dome (i.e., cleanliness flag on a scale of $1-10$, with 1 denoting perfectly clean and 10 representing complete blocking) and (ii) horizontal alignment status based on the position of bubble in the spirit level of the leveling plate (i.e., tilt flag on a scale of 1-3), were noted for each station. The tilt flag 1 denotes perfect alignment with bubble located within the marked cir- 
Table 2. Classification details of observational flags.

\begin{tabular}{llll}
\hline $\begin{array}{l}\text { Level } \\
\text { flag }(0-3)\end{array}$ & $\begin{array}{l}\text { Cleanliness } \\
\text { flag }(0-10)\end{array}$ & $\begin{array}{l}\text { Observational } \\
\text { flag (1-4) }\end{array}$ & Remarks \\
\hline 1 & 1 & 1 & Good \\
\hline 1 & $2-4$ & 2 & $\begin{array}{l}\text { Okay, but sometimes } \\
\text { spurious }\end{array}$ \\
2 & $1-4$ & & $\begin{array}{l}\text { Bad or ignore } \\
\text { completely }\end{array}$ \\
\hline 1 & $>4$ & 3 & Missing or no observations \\
\hline 3 & $1-10$ & & \\
\hline 0 & 0 & 4 &
\end{tabular}

cle, 2 is medium alignment with bubble partially located in and out of the marked circle, and 3 represents bad alignment with the bubble completely located out of the marked circle. Examples of level reading warranting tilt flags 1,2, and 3 are shown in Fig. S1. In case of missing or no observation of both cleanliness and horizontal misalignment status, they were assigned zero flags. This information was then used to assign an observational flag (on a scale of 1-4) to the entire previous week's data of corresponding station. Table 2 outlines the criteria adopted for assigning these observational flags. Over the entire HOPE period, it was observed that more than 80 stations $(\sim 80 \%)$ always had good data (i.e., observational flag $=1$ ) on any day.

\subsection{Uncertainty assessment}

The accuracy of global irradiance measurements from an EKO silicon photodiode pyranometer depends not only on the specifications of the sensor (including the calibration procedure) but also on the measurement and maintenance protocol along with the prevailing environmental conditions. The measurement system includes a pyranometer sensor, analogto-digital conversion (ADC) modules including an amplifier, and a data logger unit as described in Sect. 2.1. The uncertainty of the whole system is a combination of uncertainties from various components. In general, the measurement system is assumed to have intrinsic, calibration, and operational uncertainties. These uncertainty calculations are dependent on the distribution of uncertainty sources (Reda, 2011; Vuilleumier et al., 2014). If a Gaussian distribution is assumed for measurement values, then the "standard uncertainty" is equivalent to the standard deviation $(\sim 68 \%$ values are included in \pm 1 standard deviation interval around the true value). When the limits of deviation encompasses a large fraction of the distribution of the measured values ( $\sim 95 \%$ values, which in case of a Gaussian distribution of the measured values is about twice the standard uncertainty), this is referred as "expanded uncertainty". Hereafter, we denote the standard uncertainties with " $u$ " and expanded uncertainties by " $U$ ". Further information on uncertainty calculations for different distributions of measurement values are given in Reda (2011) and Habte et al. (2014). Detailed de- scription about the uncertainty assessment of measurements from an EKO photodiode pyranometer was included in the Supplement, while a brief overview of the methods adopted for estimating these uncertainties from different sources and resulting estimates is presented in the following subsections.

\subsubsection{Intrinsic sensor and calibration uncertainties}

Intrinsic sensor uncertainties are those associated with the measurement sensor characteristics and other components of the observing system such as ADC data logger and amplifier that can influence the measurement signal or equation. Table 1 presents the characteristics of various components involved in the measurement system.

The uncertainty associated with the process of calibration involve the uncertainties of the initial reference and transfer sensors used during calibration. This is mainly dominated by the uncertainties in the spectral sensitivity of various sensors involved in the calibration process. For our EKO photodiode sensors, the calibration factors $\left(K_{\mathrm{c}}\right)$ ranged from 6.71 to $7.67 \mu \mathrm{V} \mathrm{W}^{-1} \mathrm{~m}^{2}$ with a mean value of $7.375 \mu \mathrm{V} \mathrm{W}^{-1} \mathrm{~m}^{2}$ and a standard deviation of $\pm 0.22 \mu \mathrm{V} \mathrm{W}^{-1} \mathrm{~m}^{2}(\sim 3 \%)$. These calibration factors were determined from a solar simulator with a standard spectrum. Errors are introduced when the spectral composition of the measured irradiance in the field deviates from that of the solar simulator since the spectral sensitivity $\eta$ (Eq. 4) is not uniform. As a consequence, the measurement error typically can be $5 \%$ for higher solar zenith angles (see Table 1). The accuracy of global irradiance measurements from a silicon photodiode sensor depends on the systematic influences associated with the solar spectrum, solar zenith angles, and detector temperature that affect the signal-to-noise ratio (e.g., Dirmhirn, 1968; Michalsky et al., 1987, 1991; King et al., 1998; Myers, 2011; Sengupta et al., 2012). Further, the stability of calibration is expected to change by about $1 \%$ over a year, and thus these sensors need to be re-calibrated once every 2 years.

\subsubsection{Operational uncertainties}

The uncertainties arising from different external sources associated with the operational conditions and the level of maintenance are referred to as operational uncertainties. Typical sources of operational uncertainties were mentioned in Sect. 3.2. Details of the methods adopted to examine these operational sources of uncertainty affecting real-time measurement are described as follows.

i. Soiling of sensors is an important source of underestimating the global irradiance measurements, especially when a daily maintenance is not feasible for a dense network of pyranometers. Soiling is not predictable and there is no accurate method for its correction. Lack of knowledge about soiling characteristics and prevailing state of the surface and surrounding conditions around the radiation sensors lead to further complications. Oc- 
currence of slight rainfall during dusty air events soil the sensors, while heavy precipitation events, in contrast, clean them. Sometimes, the glass domes were affected by the bird droppings. In such cases, it is extremely hard to remotely monitor the extent of soiling or bird droppings overlying on the glass dome during the periods when there is no maintenance activity. So, we define the relative soiling factor or the relative rise in the signal $\left(\delta_{\mathrm{S}}\right)$ as

$\delta_{\mathrm{S}}=1-\frac{G_{\mathrm{b}}}{G_{\mathrm{a}}}$,

where $G_{\mathrm{b}}$ and $G_{\mathrm{a}}$ correspond to the instantaneous global irradiance measurements at $\pm 5 \mathrm{~min}$ "before" and "after" cleaning of the glass dome. From our observations, we found that there is no dependency of $\delta_{\mathrm{S}}$ with the cleanliness flags (see Fig. S2). This indicates a possible inconsistency when assigning the cleanliness flags from different observers. During HOPE, a standard uncertainty of $\pm 15 \mathrm{~W} \mathrm{~m}^{-2}$ was assigned instead of the cleanliness flag.

ii. Horizontal misalignment of the sensor leveling plate results in an error that is mainly dependent on the solar zenith angle $\left(\theta_{0}\right)$ and the corresponding angle of deviation (Wendisch et al., 2001). In our case, there are only two levels of misalignment corresponding to tilt flags 2 and 3. Thus, we define the relative deviation in the global irradiance measurements due to horizontal misalignment $\left(\delta_{T}\right)$ as

$\delta_{T}=\left(1-\frac{G_{\mathrm{tb}}}{G_{\mathrm{tu}}}\right) \cdot 100 \%$,

where $G_{\mathrm{tb}}$ and $G_{\mathrm{tu}}$ represent the "biased" and "unbiased" measurements from respective sensors. In order to determine the relative deviation due to horizontal misalignment $\left(\delta_{T}\right)$, we have set up three pyranometers sensors with the three possible levels of alignment in accordance to our classification of tilt flags (refer Fig. S1). The standard uncertainty due to horizontal misalignment was obtained by considering both the width and the median bias of the percent relative deviation. From our observations, standard uncertainties of 3.12 and $3.95 \%$ were assigned to the biased measurements corresponding to tilt flags 2 and 3 with respect to the perfectly leveled measurement with tilt flag 1 (see Fig. S3). The dependence of $\delta_{T}$ on solar zenith angle is neglected.

iii. Close by structures at each measurement site influence the global horizontal irradiance at higher solar zenith angles. On any cloudless day, these are readily detectable. An exact correction is possible if there exist simultaneous measurements of both the diffuse and global irradiance components at each measurement site. As there were no measurements of the diffuse component available at any site, we have applied the clear-sky empirical fitting method (Long and Ackerman, 2000) on the clear-sky measurements of global irradiance from each station. We found large differences $\left(\gtrsim 50 \mathrm{~W} \mathrm{~m}^{-2}\right.$ ) between the modeled and the actual measurements when obstructions were close to the pyranometer station. These differences are more significant at solar elevation angles less than $15^{\circ}$. For this reason, to avoid any shadowing effect due to close by structures, the data analysis was limited to $\theta_{0}<75^{\circ}$. However, there were around five stations whose measurements were influenced for elevation angles greater than $15^{\circ}$ (refer Sect. S1.2.3 in the Supplement).

iv. Intercomparison of all EKO photodiode pyranometers provide the deviation in global irradiance measurements among similar sensors during all sky conditions. This relative deviation was obtained from the ratio of standard deviation to the corresponding mean values. It was observed that the relative deviation of $G$ (in \%) increases linearly with the solar zenith angle $\left(49^{\circ}<\theta_{0}<75^{\circ}\right)$. The corresponding frequency distribution of the deviation in $G$ from all EKO pyranometers indicate a maximum uncertainty of less than $5 \%$ under variable sky conditions (see Figs. S4 and S5).

\subsubsection{Combined uncertainty estimation}

All the sources of uncertainty (as described in Sect. 3.3.1 and 3.3.2) are combined together to derive the standard uncertainty in the global horizontal irradiance $\left(u_{\mathrm{G}}\right.$ in $\left.\mathrm{Wm}^{-2}\right)$ as below:

$u_{G}=\sqrt{c_{K}^{2} \cdot u_{K}^{2}+c_{V}^{2} \cdot u_{V}^{2}+c_{A}^{2} \cdot u_{A}^{2}+u_{\mathrm{stat}}^{2}+\sum u_{\mathrm{op}}^{2}}$,

where $c_{K}=\frac{\partial G}{\partial K_{\mathrm{c}}}, c_{V}=\frac{\partial G}{\partial V}$, and $c_{A}=\frac{\partial G}{\partial A}$ are sensitivity factors for pyranometer sensitivity $\left(K_{\mathrm{c}}\right)$, raw voltage signal $(V)$, and amplification factor $(A)$, respectively, while $u_{K}, u_{V}$, and $u_{A}$ are corresponding standard uncertainties. In Eq. 8, the term $u_{\text {stat }}$ denotes the measurement uncertainty derived from the width of the distribution obtained when sampling a stable quantity multiple times with the measurement system. Since the raw signal from the pyranometer sensor was obtained at $10 \mathrm{~Hz}$ frequency, the conversion to $1 \mathrm{~Hz}$ resolution indicated a statistical uncertainty of $\pm 4 \mathrm{~W} \mathrm{~m}^{-2}$. The term $u_{\text {op }}$ denotes the operational uncertainties listed in Sect. 3.3.2.

In order to compute the uncertainty estimates of global transmittance, an error estimate of $\pm 0.5 \mathrm{~W} \mathrm{~m}^{-2}$ in the climate significant total solar irradiance value at the TOA (Kopp and Lean, 2011) and $\pm 0.05^{\circ}$ in the calculation of solar zenith angle $\left(\theta_{0}\right)$ were considered.

A summary of the combined standard and expanded uncertainty estimates for different conditions were listed in Table 3 for both global horizontal irradiance $(G)$ and corresponding derived global transmittance $(T)$ measurements (see Sect. S1.3 and Tables S1 and S2 in the Supplement). 
Table 3. Standard and expanded uncertainties of global horizontal irradiance $(G)$ and derived global transmittance $(T)$.

\begin{tabular}{|c|c|c|c|c|}
\hline \multirow[t]{2}{*}{ Variables/condition } & \multicolumn{2}{|c|}{ Standard uncertainty $\left(u_{i}\right)$} & \multicolumn{2}{|c|}{ Expanded uncertainty $^{\mathrm{a}}\left(U_{i}\right)$} \\
\hline & Small $^{\mathrm{b}}$ & Large $^{c}$ & Small & Large \\
\hline $\begin{array}{l}\text { Global horizontal irradiance }(G) \\
\text { (at } 30 \text { and } 80^{\circ} \text { angles of incidence) }\end{array}$ & $\mathrm{W} \mathrm{m}^{-2}$ & $\mathrm{~W} \mathrm{~m}^{-2}$ & $\mathrm{~W} \mathrm{~m}^{-2}$ & $\mathrm{~W} \mathrm{~m}^{-2}$ \\
\hline $\begin{array}{l}\text { Measurement equation } \\
\text { (i.e., } u_{\text {op }}=0 \text { and } u_{\text {stat }}=0 \text { ) }\end{array}$ & $1.8-5.2$ & $35.3-104.4$ & $3.5-10.2$ & $69.2-204.6$ \\
\hline+ Statistical correction & $4.4-6.6$ & $35.5-104.5$ & $8.6-12.9$ & 69.6-204.8 \\
\hline + Intercomparison uncertainty & $4.6-6.7$ & $43.4-107.4$ & $9.02-13.1$ & $85.1-210.5$ \\
\hline+ Tilt flag $=1$ and soiling & $15.7-16.4$ & $45.9-108.5$ & $30.7-32.1$ & $89.9-212.7$ \\
\hline+ Tilt flag $=2$ and soiling & $15.75-16.5$ & $55.5-112.9$ & $30.8-32.4$ & $108.8-221.3$ \\
\hline+ Tilt flag $=3$ and soiling & $15.8-16.6$ & $60.6-115.5$ & $30.9-32.4$ & $118.7-226.3$ \\
\hline
\end{tabular}

Global transmittance $(T)$

(at 30 and $80^{\circ}$ angles of incidence)

\begin{tabular}{lrrrr}
\hline Measurement equation & $0.0013-0.0038$ & $0.026-0.077$ & $0.0025-0.0075$ & $0.051-0.151$ \\
(i.e., $u_{\text {op }}=0$ and $\left.u_{\text {stat }}=0\right)$ & & & & \\
+ Statistical correction & $0.0032-0.0049$ & $0.026-0.077$ & $0.0063-0.0096$ & $0.051-0.151$ \\
+ Intercomparison uncertainty & $0.0034-0.005$ & $0.032-0.079$ & $0.0067-0.01$ & $0.063-0.155$ \\
+ Tilt flag = 1 and soiling & $0.0115-0.012$ & $0.034-0.08$ & $0.023-0.024$ & $0.067-0.157$ \\
+ Tilt flag = 2 and soiling & $0.0116-0.012$ & $0.041-0.083$ & $0.023-0.024$ & $0.08-0.16$ \\
+ Tilt flag $=3$ and soiling & $0.0116-0.012$ & $0.045-0.085$ & $0.023-0.024$ & $0.09-0.17$
\end{tabular}

a Expanded uncertainty $\left(U_{i}\right)$ with $95 \%$ confidence level is obtained by multiplying standard uncertainties $\left(u_{i}\right)$ with a coverage factor ( $k=1.96)$ for infinite degrees of freedom.

b Small signal correspond to $50 \mathrm{~W} \mathrm{~m}^{-2}$ of global horizontal irradiance $(G)$.

${ }^{\mathrm{c}}$ Large signal correspond to $1000 \mathrm{~W} \mathrm{~m}^{-2}$ of global horizontal irradiance $(G)$.

\section{Results and discussion}

A total of 18 intensive observation periods with variable sky condition were identified between April and May 2013. During this period, the daily mean temperature was observed to be $283.65 \mathrm{~K}$ with a minimum of $270.95 \mathrm{~K}$ and a maximum of $297.95 \mathrm{~K}$. Most of the overcast days were accompanied by precipitation. For the April-May period, the measured total precipitation was $114.7 \mathrm{~mm}$. In the following sub-sections, the spatiotemporal measurements of global transmittance are assessed on different days with homogeneous and inhomogeneous sky conditions. The statistical parameters from the time series of global transmittance measurements from the collocated thermopile and the nearest EKO photodiode pyranometers are compared. Finally, the instantaneous spatial inhomogeneity in global transmittance fields are assessed with the corresponding sky images (movies included in the Supplement).

\subsection{Clear sky - 4 May 2013}

It is essential to understand the consistency in the clear-sky global transmittance among a large number of measurement stations as it offers the possibility for validating the existing clear-sky models. These models are required to study the more complicated cloudy skies in terms of the cloud radiative forcing.
In Fig. 4a, the instantaneous spatial distribution of the derived global transmittance on a clear-sky day (4 May 2013) is shown along with the corresponding sky image (Fig. 4b) obtained at the LACROS site. On this day, a few high-altitude cirrus clouds were observed in the morning and thereafter perfect clear-sky conditions prevailed with weak westerly winds. The difference between minimum and maximum values in the spatial distribution of RH and ambient air temperature measurements varied from 10 to $20 \%$ and 6 to $8 \mathrm{~K}$, respectively, during the day. At noon ( $\sim$ 14:00 UTC), RH varied from 35 to $55 \%$, while ambient air temperatures ranged from 289 to $295 \mathrm{~K}$ in the observation domain.

The temporal variability of the mean, median, minimum, and maximum values of the derived global transmittance from the spatial distribution is shown in Fig. 4c. During this day, the relative standard deviation (or the ratio of standard deviation to the mean) of the derived global transmittance measurements from the pyranometer network varied from 2.6 to $19.7 \%$. Apart from the contribution due to aerosols on a clear-sky day, the large spread in the morning and evening times can be attributed to the larger directional errors associated with an EKO pyranometer at lower solar elevation angles. We have also observed that a few stations were influenced by the background shadowing from surrounding obstructions (see movie01.avi in the Supplement) in spite of limiting the data analysis to solar zenith angles larger than $75^{\circ}$. Additional short-time decrements in transmittance from 

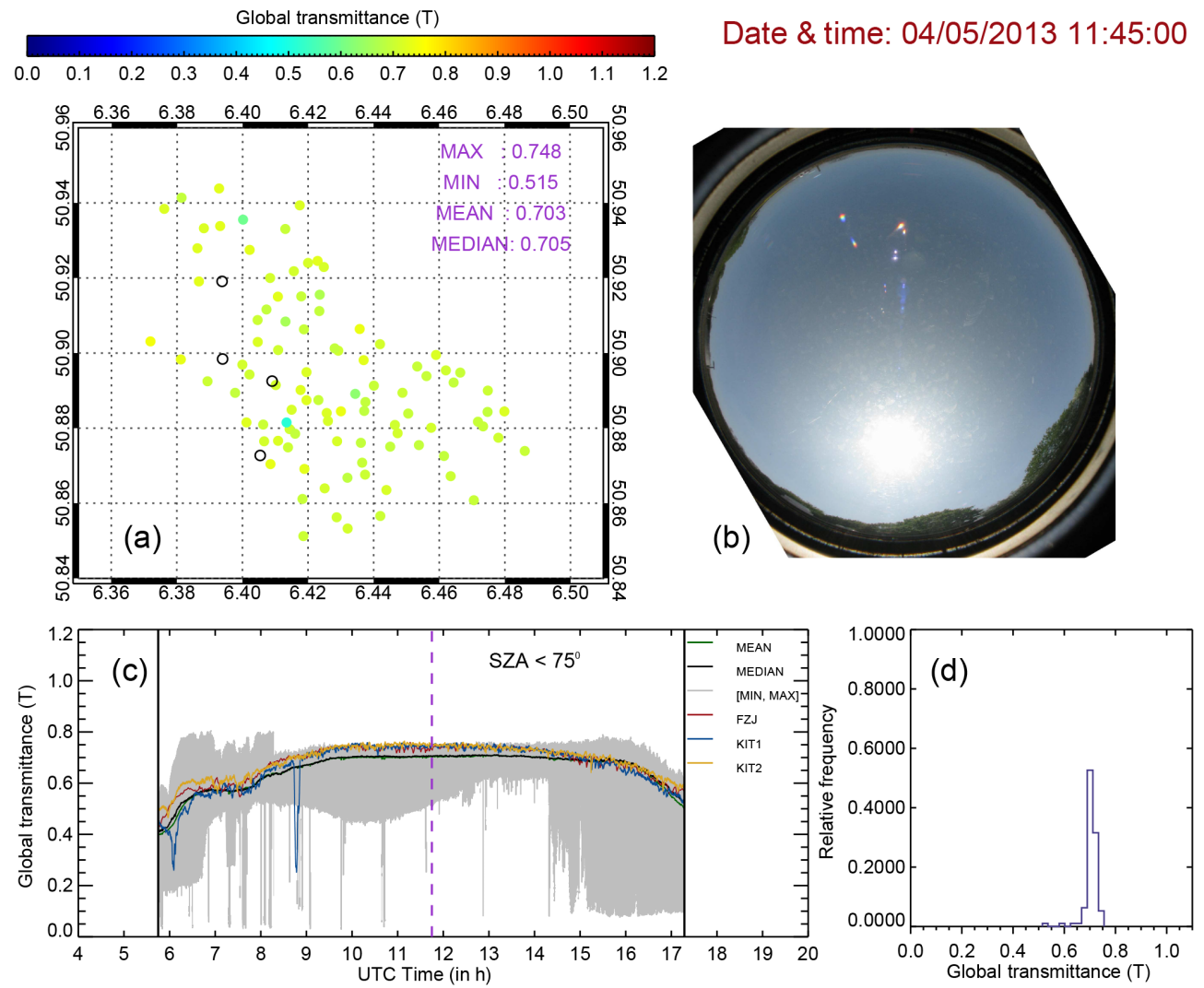

Figure 4. Clear sky on 4 May 2013: (a) spatial distribution of derived global transmittance field with corresponding (b) sky imager snapshot at LACROS site for 11:45:00 UTC. (c) Temporal variability in the mean, median, minimum, and maximum values of the derived spatial global transmittance values. (d) Relative frequency distribution of the spatial transmittance field shown in (a). Missing stations are represented with open circles in (a) and the dashed pink line in (c) denotes the time of observation for (a, $\mathbf{b}$, and $\mathbf{d})$.

some stations may result from random resting of birds. Absolute differences between the mean and median values of derived global transmittance in the spatial domain are spread between 0.0 and 0.03 as a function of time. This implies that the spatial distribution is evenly centered around the mean with few outliers.

The time series comparison of derived global transmittance values from collocated thermopile pyranometers (i.e., FZJ, KIT1, KIT2) with our close-by stations showed a very good matchup (see Table 4). Though the linear correlation $(r>0.92)$ and the slope of regression $(>0.80)$ are always high and complemented each other, the root mean square error (RMSE) varied from 4.2 to $11.1 \%$. Further, an approximate difference of $5 \%$ was observed consistently between the mean spatial transmittance from the network and the measurements from the collocated thermopile pyranometers especially during 09:00-15:00 UTC. The frequency distribution of instantaneous global transmittance values from the spatial domain (shown in Fig. 4d) indicated a dominant peak varying between 0.4 and 0.7 .

\subsection{Broken cloudy sky - 5 May 2013}

Under broken-cloud conditions, the pyranometer views a portion of the clear-sky or even direct sunlight. As a result of this, the intensity of diffuse irradiance is mainly determined by the presence or absence of cloud patches in the vicinity of the Sun and their optical thickness. If the clouds are not too thick, then the diffuse irradiance from a clear sky is smaller than that of a cloudy sky. Broken clouds vary considerably in their horizontal and vertical extents. A nonhomogeneous thicker cloud (or a portion of the cloud that is relatively thick) loses solar energy due to scattering at the cloud edges, eventually complicating the determination of flux absorbed in a cloud layer due to net horizontal photon transport. Consequently, both the reflection and transmission are reduced relative to a plane-parallel cloud of the same cloud thickness and microphysics. However, under clear or partially cloudy conditions, both reflection and transmission are enhanced by the incoming photons scattered by the neighboring thick clouds. Subsequently, the uncertainties in the input parameters required for radiative transfer calculations result in errors that are comparable or even larger than the discrepancies between the observed and computed cloud ab- 
Table 4. Comparison of statistical parameters between the time series global transmittance $(T)$ measurements of collocated thermopile pyranometers with the nearest EKO pyranometers in the network. Here RMSE represents root mean square error.

\begin{tabular}{llrrr}
\hline Day/sky condition & Parameter & FZJ vs. PYR76 & KIT1 vs. PYR71 & KIT2 vs. PYR98 \\
\hline & Spatial separation $(\mathrm{m})$ & 29.5 & 227.5 & 343.5 \\
\hline 4 May 2013 & correlation $(r)$ & 0.98 & 0.93 & 0.95 \\
(clear sky) & RMSE & 0.0423 & 0.0421 & 0.111 \\
& slope & 0.92 & 0.81 & 0.85 \\
& $y$ intercept & 0.014 & 0.11 & -0.008 \\
\hline 5 May 2013 & correlation $(r)$ & 0.99 & 0.78 & 0.512 \\
(broken cloudy sky) & RMSE & 0.034 & 0.087 & 0.161 \\
& slope & 0.92 & 0.7 & 0.46 \\
& $y$ intercept & 0.028 & 0.19 & 0.27 \\
\hline 30 May 2013 & correlation $(r)$ & 0.997 & 0.83 & 0.87 \\
(overcast sky) & RMSE & 0.023 & 0.09 & 0.09 \\
& slope & 0.94 & 0.75 & 0.81 \\
& $y$ intercept & 0.0013 & 0.42 & 0.04 \\
\hline
\end{tabular}

sorptions. Thus, the cloud inhomogeneity has a significant influence on the broadband solar fluxes (e.g., Long and Ackerman, 2000; Scheirer and Macke, 2003).

The instantaneous spatial distribution of the derived global transmittance on a broken cloudy day (5 May 2013) is shown in Fig. 5a along with the corresponding sky image (Fig. 5b). During this day, clear-sky conditions prevailed until 09:00 UTC. Thereafter, slightly increasing cloudiness with cumulus humilis was observed. The winds turned from the south in the morning to west during noon and then to the north. The differences between minimum and maximum values in the spatial distribution of RH and ambient air temperature measurements varied from 10 to $20 \%$ and 6 to $8 \mathrm{~K}$, respectively, during the day. At noon ( $14: 00 \mathrm{UTC})$, the RH and air temperature measurements varied from 35 to $60 \%$ and 291 to $297 \mathrm{~K}$, respectively, in the observation domain.

The temporal variability in the mean, median, minimum, and maximum values of the derived global transmittance from the spatial domain is shown in Fig. 5c. During this day, the relative standard deviation in the derived global transmittance measurements from the pyranometer network varied from 4.0 to $40.9 \%$ (see movie02.avi in the Supplement). The large spatial heterogeneity in global transmittance values is more pronounced through the incoherent variability between different thermopile pyranometers (at FZJ, KIT1, and KIT2) in addition to the large deviation observed from the pyranometer network. Occasional decoupling between the mean and median time series occurred when the sky was covered with broken clouds. As a result, absolute differences between the mean and median values of the derived global transmittance values varied between 0.0 and 0.14 as a function of time, indicating the presence of skewed distributions with outliers that are not symmetrical.
The time series comparison of the derived global transmittance values from collocated thermopile pyranometers with our close-by stations indicated remarkable differences in the observed statistical parameters during the periods of brokencloud cover (Table 4). This implies that the spatial collocation distance between the comparison pyranometers is sensitive under nonhomogeneous sky conditions. As the distance between the comparison pyranometers increases, the linear correlation $(r)$ and the slope of the regression decreases while the RMSE increases. The frequency distribution of instantaneous spatial global transmittance values (Fig. 5d) indicate a bimodal distribution with a dominant peak at higher transmittance value $(\sim 0.7)$ and an insignificant peak at lower transmittance value $(\sim 0.2)$. The dominance of a peak at higher transmittance values possibly indicate the prevalence of a more open clear-sky portions relative to the cloud cover.

\subsection{Overcast sky - 30 May 2013}

An overcast sky is characterized by relatively lower global irradiance than that of a clear-sky situation at any wavelength. Atmospheric transmission can be reduced to less than $10 \%$ of its clear-sky value under thick overcast conditions and the downward radiance distribution is almost independent of the direction.

The instantaneous spatial distribution of the derived global transmittance on an almost overcast day (30 May 2013) is shown in Fig. 6a along with the corresponding sky image (Fig. 6b). During this day, strong cloudiness prevailed mostly with few clearings in between. Winds from the south were prevailing throughout the day. As there was rain in the previous night and early morning, significant differences between the minimum and maximum values of RH were observed (20 to $40 \%$ ) while ambient air temperature remained consistent and homogeneous $(\sim 6 \mathrm{~K})$ throughout the day. Though $\mathrm{RH}$ 

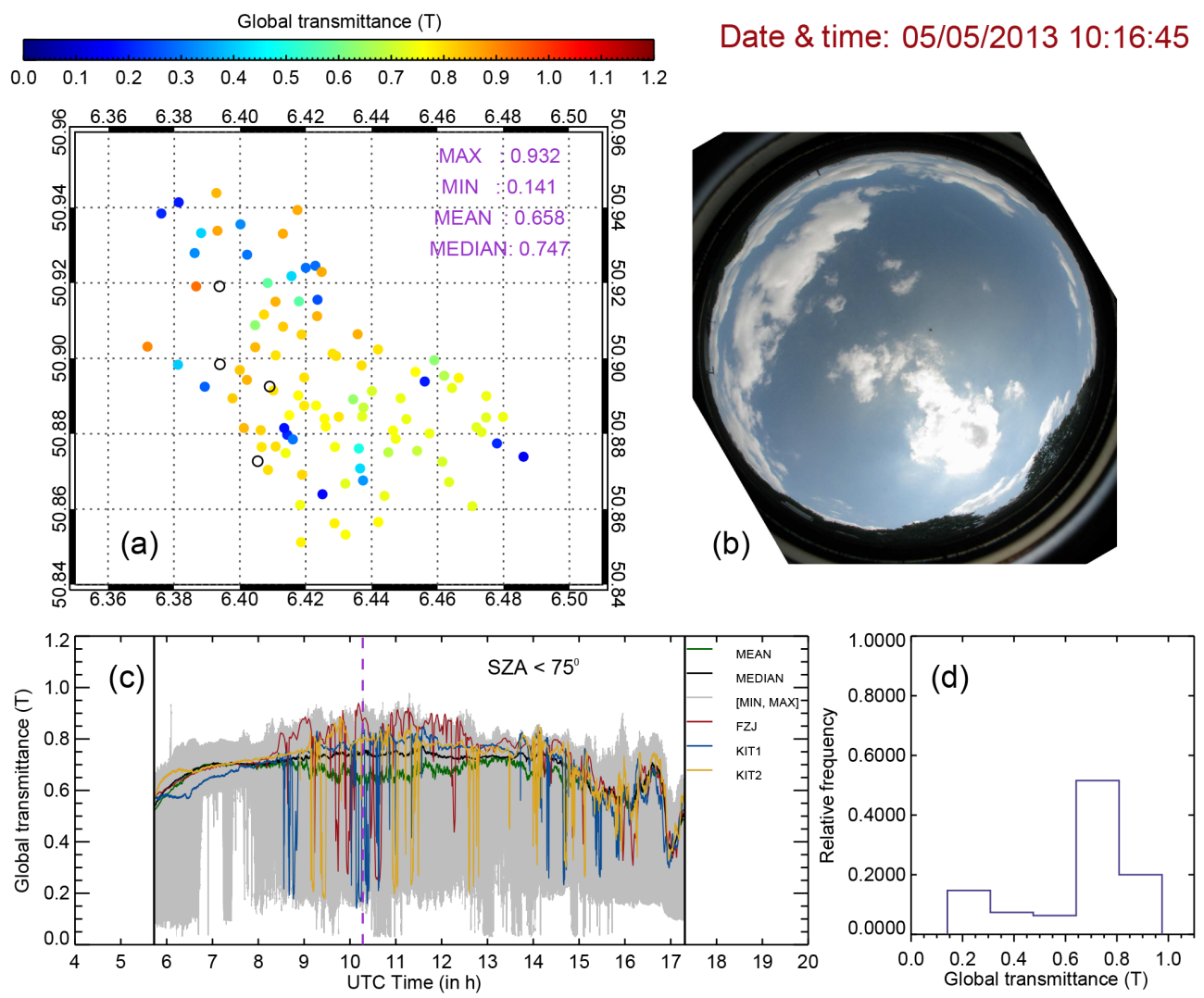

Figure 5. Broken cloudy sky on 5 May 2013: (a) spatial distribution of derived global transmittance field with corresponding (b) sky imager snapshot at LACROS site for 10:16:45 UTC. (c) Temporal variability in the mean, median, minimum, and maximum values of the derived spatial global transmittance values. (d) Relative frequency distribution of the spatial transmittance field shown in (a). Missing stations are represented with open circles in (a) and the dashed pink line in (c) denotes the time of observation for (a, b, and $\mathbf{d})$.

measurements varied between 40 and $80 \%$, ambient air temperature measurements were less variable ( 280 to $286 \mathrm{~K}$ ) during the day in the observation domain.

The temporal variability in the mean, median, minimum, and maximum values of the derived global transmittance from the spatial domain is shown in Fig. 6c. On this day, the relative standard deviation in the derived global transmittance measurements from the pyranometer network varied from 7.6 to $75.1 \%$ (movie03.avi in the Supplement). Large deviations indicate the prevalence of nonhomogeneous and variable conditions in the sky. The absolute differences between the mean and median values of the derived global transmittance varied similar to broken cloudy conditions (between 0.0 and 0.14 ) indicating the presence of skewed distributions with outliers that are not symmetrical. Throughout the day, the dominance of lower global transmittance values $(<0.5)$ in the spatial domain indicate thick overcast cloud cover in the sky. Very high global transmittance values ( $>1.0$ ) were also observed in the morning before 08:30 UTC during the periods of short clearances in the sky (i.e., broken clouds). At this time, the global horizontal irradiance observed at the surface was higher for some stations than the corresponding values at the TOA. It is possible that for short time periods under broken cloudy conditions, the downward global irradiance at the surface can be larger than that at the TOA due to the scattering of photons from the cloud edges (i.e., broken-cloud effect) that are not in the way of incident solar beam (Schade et al., 2007). This was also pronounced with the collocated thermopile pyranometers (at KIT1 and KIT2).

The time series comparison of the derived global transmittance from thermopile pyranometers with nearby network stations indicated a high linear correlation, $r>0.82$ (Table 4). The frequency distribution of instantaneous global transmittance values from the network (Fig. 6d) indicated a monomodal distribution with one dominant peak lying towards lower transmittance values $(\sim 0.3)$ during overcast conditions. However, during shorter clearances (before 08:30 UTC) with broken clouds a bimodal distribution was observed with a dominant peak towards lower transmittance values. 

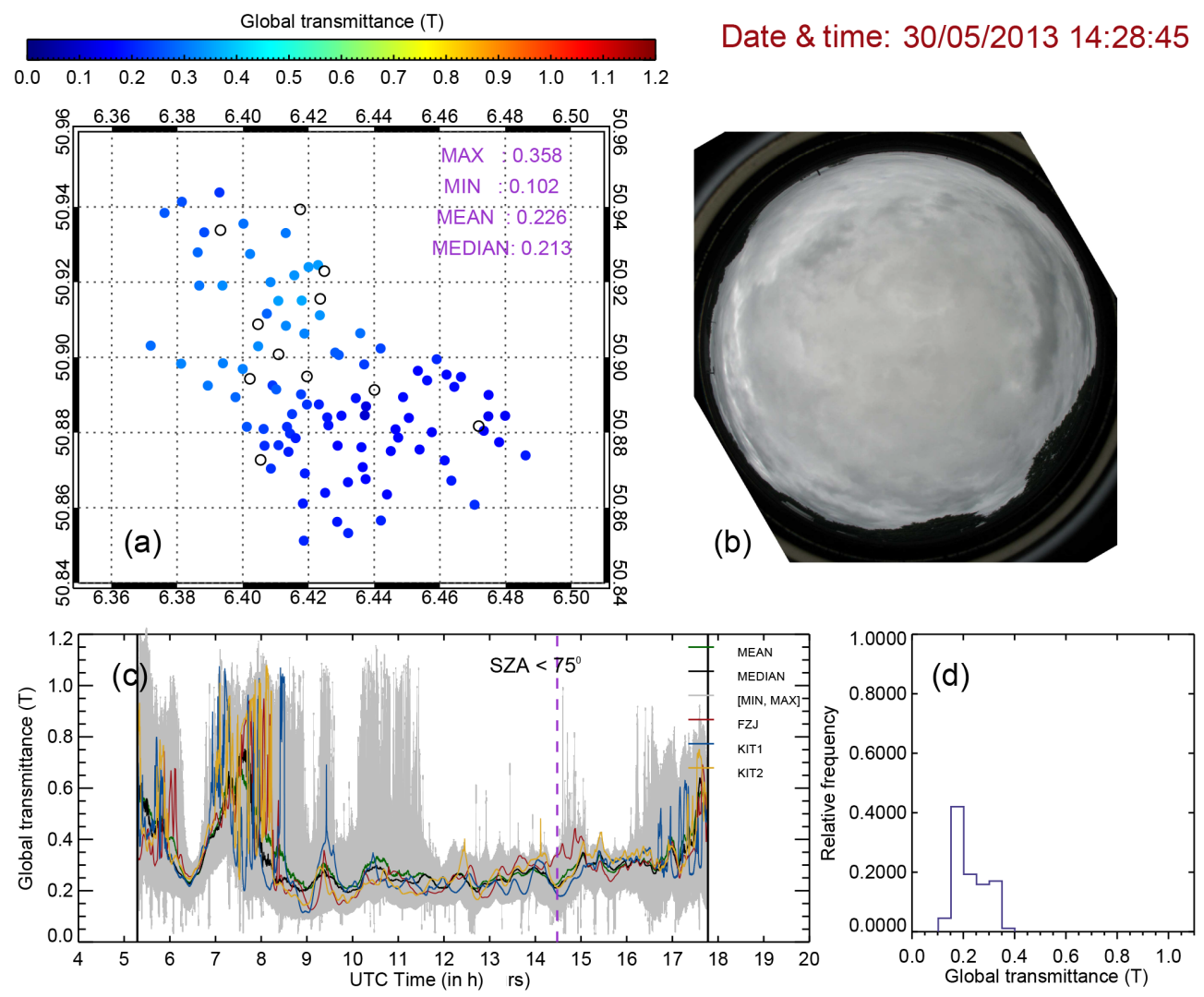

Figure 6. Overcast sky on 30 May 2013: (a) spatial distribution of derived global transmittance field with corresponding (b) sky imager snapshot at LACROS site for 14:28:45 UTC. (c) Temporal variability in the mean, median, minimum, and maximum values of the derived spatial global transmittance values. (d) Relative frequency distribution of the spatial transmittance field shown in (a). Missing stations are represented with open circles in (a) and the dashed pink line in (c) denotes the time of observation for (a, b, and $\mathbf{d})$.

\section{Conclusions and outlook}

The spatial and temporal distribution of shortwave global irradiance measurements obtained at the surface during HOPE campaign with unprecedented resolution provides a unique observational data set aimed at capturing the small-scale modulations of radiation due to clouds and their inhomogeneity. This paper demonstrates the importance of a smallscale, high-density surface radiation network and presents the first results of the spatiotemporal variations in the derived global transmittance measurements. Details of the data processing and possible uncertainty estimates under variable (or operational) conditions were presented. Summarizing, the preliminary observations are outlined as below.

i. Significant spatial and temporal variability in the derived global transmittance fields was observed during broken cloudy conditions.

ii. A distinct monomodal spatial distribution of global transmittance was observed for a homogeneous clear and overcast sky conditions. The spread of the transmittance distribution increased with the solar zenith angle.
It varied between 0.1 and 0.25 transmittance by excluding the stations influenced with background shadowing.

iii. A bimodal spatial distribution of global transmittance was observed with a dominant peak characterized by the relative contribution due to clear and cloudy portions of the sky. Larger spread of the transmittance distribution $(\sim 0.8)$ was observed during inhomogeneous broken cloudy conditions.

Extensive spatiotemporal analysis between the cloudinduced transmittance fields derived from the pyranometer network and the corresponding TOA reflectance measurements from the high-resolution broadband channel (0.4$1.1 \mu \mathrm{m})$ of the Meteosat SEVIRI can possibly ensure the quality of our measurements. Most importantly, by performing multi-scale analysis (Deneke et al., 2009) of these measurements from the HOPE campaign, the optimal spatial and temporal resolutions required for probing the small-scale cloud radiative effects under different cloud regimes in the sky can be investigated. A recent study by Hinkelman (2013) found that the correlation between the irradiances at two different sites depends on the orientation of the axis between 
them relative to the wind direction and on their spatial separation.

During the HOPE campaign, state-of-the-art remote sensing instrumentation was used to observe a large atmospheric volume with high frequency. This experiment will allow for the $\mathrm{HD}(\mathrm{CP})^{2}$ model evaluation at the scale of the simulations. In this context, a radiative closure study is an essential tool to evaluate the accuracy of atmospheric retrievals (e.g., cloud and aerosol properties) and measurement techniques. Radiative transfer models can also be validated through focused closure studies using well-defined cases and high-quality measurements. While the clear-sky radiation field over a homogeneous surface is well understood and can be simulated with 1-D radiative transfer, the situation becomes more challenging for broken and inhomogeneous cloud fields. The quality-controlled measurements from our pyranometer network will be used to perform radiative closure studies using the simulated cloud-induced shortwave surface radiation fields from the 3-D Monte Carlo radiation transfer code (Macke et al., 1999). To this end, observed cloud fields and those from an existing large eddy simulation model at different spatial scales will be used as input in the Monte Carlo radiation transfer to understand the uncertainty between the simulated vs. the observed cloud radiative forcing and thus improve the radiation parametrizations at sub-scales for better climate prediction.

\section{The Supplement related to this article is available online at doi:10.5194/amt-9-1153-2016-supplement.}

Acknowledgements. The authors acknowledge essential technical support from the TROPOS mechanics and electronics workshops in designing and building the autonomous pyranometer, especially Cornelia Kurze and Hartmut Haudek. Many thanks to all the private landowners for their support. We are grateful to Research Center Jülich (FZJ) for valuable logistic support in setting up and maintaining the instruments. The first author's work was funded by Federal Ministry of Education and Research (BMBF), Germany, as part of $\mathrm{HD}(\mathrm{CP})^{2}$ project. We also thank our colleagues Hartwig Deneke, Sebastian Bley, Felix Dietzsch, Daniel Merk, Jonas Walther, Alexander Graf (FZJ), Michael Eickmeier, and Felix Peintner for extending their support during HOPE campaign. We thank Birger Bohn from FZJ and Katja Träumner, Vera Maurer, and Norbert Kalthoff from KIT for sharing their pyranometer data sets. We appreciate the support provided by Alexander Los and Kees Hogendijk from EKO Instruments, the Netherlands. We also thank the anonymous reviewers for their helpful comments and suggestions on the manuscript.

Edited by: S. Schmidt

\section{References}

Augustine, J. A., DeLuisi, J. J., and Long, C. N.: SURFRAD - a national surface radiation budget network for atmospheric research, B. Am. Meteorol. Soc., 81, 2341-2357, doi:10.1175/15200477(2000)081<2341:SANSRB>2.3.CO;2, 2000.

Barker, H. W. and Li, Z.: Interpreting shortwave albedotransmittance plots: true or apparent anomalous absorption?, Geophys. Res. Lett., 24, 2023-2027, doi:10.1029/97GL02019, 1997.

Barker, H. W., Curtis, T. J., Leontieva, E., and Stamnes, K.: Optical depth of overcast cloud across Canada: estimates based on surface pyranometer and satellite measurements, J. Climate, 11, 2980-2994, doi:10.1175/15200442(1998)011<2980:ODOOCA>2.0.CO;2, 1998.

Boucher, O., Randall, D., Artaxo, P., Bretherton, C., Feingold, G., Forster, P., Kerminen, V. M., Kondo, Y., Liao, H., Lohmann, U., Rasch, P., Satheesh, S. K., Sherwood, S., Stevens, B., and Zhang, X. Y.: Clouds and aerosol, in: Climate Change 2013: The Physical Science Basis. Contributions of Working Group I to the Fifth Assessment Report of the Intergovernmental Panel on Climate Change, edited by: Stocker, T. F., Qin, D., Plattner, G.K., Tignor, M., Allen, S. K., Boschung, J., Nauels, A., Xia, Y., Bex, V., and Midgley, P. M., Tech. rep., IPCC, Cambridge University Press, Cambridge, UK, New York, NY, USA, 571-657, 2013.

Deneke, H. M., Feijt, A. J., and Roebeling, R. A.: Estimating surface solar irradiance from METEOSAT SEVIRI-derived cloud properties, Remote Sens. Environ., 112, 3131-3141, doi:10.1016/j.rse.2008.03.012, 2008.

Deneke, H. M., Knap, W. H., and Simmer, C.: Multiresolution analysis of the temporal variance and correlation of transmittance and reflectance of an atmospheric column, J. Geophys. Res., 114, D17206, doi:10.1029/2008JD011680, 2009.

Dirmhirn, I.: On the use of silicon cells in meteorological radiation studies, J. Appl. Meteorol., 7, 702-707, 1968.

Gueymard, C.: The Sun's total and spectral irradiance for solar energy applications and solar radiation models, Sol. Energy, 76, 423-452, 2004.

Habte, A., Sengupta, M., Reda, I., Andreas, A., and Konings, J.: Calibration and Measurement Uncertainty Estimation of Radiometric Data, in: Solar 2014, San Francisco, California, July 6-10, 2014, NREL/CP-5D00-62214, available at:http://www.nrel.gov/ docs/fy15osti/62214.pdf (last access: 23 February 2016), 2014.

Hinkelman, L. M.: Differences between along-wind and cross-wind solar irradiance variability on small spatial scales, Sol. Energy, 88, 192-203, doi:10.1016/j.solener.2012.11.011, 2013.

Kato, S., Hinkelman, L., and Cheng, A.: Estimate the satellite derived cloud optical thickness and effective radius errors and their effect on computed domain averaged irradiances, J. Geophys. Res., 111, 17201-17217, doi:10.1029/2005JD006668, 2006.

King, D. L., Boyson, W. E., Hansen, B. R., and Bower, W. I.: Improved accuracy for low-cost solar irradiance sensors, in: 2nd World Conference and Exhibition on Photovoltaic Solar Energy Conversion, Vienna, Austria, 6-10 July, 1947-1952, 1998.

Kopp, G. and Lean, J. L.: A new, lower value of total solar irradiance: evidence and climate significance, Geophys. Res. Lett., 38, L01706, doi:10.1029/2010GL045777, 2011. 
Koren, I., Oreopoulos, L., Feingold, G., Remer, L. A., and Altaratz, O.: How small is a small cloud?, Atmos. Chem. Phys., 8, 38553864, doi:10.5194/acp-8-3855-2008, 2008.

Liou, K. N.: An Introduction to Atmospheric Radiation, 2nd edn., vol. 84 of International Geophysics Series, Academic Press, San Diego, USA, 2002.

Long, C. N. and Ackerman, T. P.: Identification of clear skies from broadband pyranometer measurements and calculation of downwelling shortwave cloud effects, J. Geophys. Res., 105, 1560915626, doi:10.1029/2000JD900077, 2000.

Macke, A. and HOPE-Team: The $\mathrm{HD}(\mathrm{CP})^{2}$ Observational Prototype Experiment HOPE - an overview, Atmos. Chem. Phys. Discuss., in preparation, 2016.

Macke, A., Mitchell, D. L., and Bremen, L. V.: Monte Carlo radiative transfer calculations for inhomogeneous mixed phase clouds, Phys. Chem. Earth Pt. B, 24, 237-241, doi:10.1016/S14641909(98)00044-6, 1999.

Michalsky, J., Dutton, E., Rubes, M., Nelson, D., Stoffel, T., Wesley, M., Splitt, M., and DeLuisi, J.: Optimal measurement of surface shortwave irradiance using current instrumentation, J. Atmos. Ocean. Tech., 16, 55-69, doi:10.1175/15200426(1999)016<0055:OMOSSI>2.0.CO;2, 1999.

Michalsky, J. J., Harrison, L., and LeBaron, B. A.: Empirical radiometric correction of a silicon photodiode rotating shadowband pyranometer, Sol. Energy, 39, 87-96, 1987.

Michalsky, J. J., Perez, R., Harrison, L., and LeBaron, B. A.: Spectral and temperature correction of silicon photovoltaic solar radiation detectors, Sol. Energy, 47, 299-305, 1991.

Myers, D. R.: Quantitative analysis of spectral impacts on silicon photodiode radiometers, in: SOLAR 2011, NREL/CP-550050936, Raleigh, North Carolina, available at: http://www.nrel. gov/docs/fy11osti/50936.pdf (last access: 23 February 2016), 2011.

Ohmura, A., Dutton, E. G., Forgan, B., Fröhlich, C., Gilgen, H., Hegner, H., Heimo, A., König-Langlo, G., McArthur, B., Müller, G., Philipona, R., Pinker, R., Whitlock, C. H., Dehne, K., and Wild, M.: Baseline Surface Radiation Network (BSRN/WCRP): new precision radiometry for climate research, B. Am. Meteorol. Soc., 79, 2115-2136, doi:10.1175/15200477(1998)079<2115:BSRNBW>2.0.CO;2, 1998.

Pinker, R. T., Frouin, R., and Li, Z.: A review of satellite methods to derive surface shortwave irradiance, Remote Sens. Environ., 51, 108-124, doi:10.1016/0034-4257(94)00069-Y, 1995.

Reda, I.: Method to calculate uncertainties in measuring shortwave solar irradiance using Thermopile and Semiconductor solar radiometers, National Renewable Energy Laboratory, CO, USA, available at: http://www.nrel.gov/docs/fy11osti/52194.pdf (last access: 23 February 2016), 2011.
Robles Gil, S.: The socio-economic benefits of climatological services to the renewable energy sector, WMO Bulletin, Geneva, Switzerland, Tech. Rep., 56, 40-45, 2007.

Roebeling, R. A., van Putten, E., Genovese, G., and Rosema, A.: Application of Meteosat derived meteorological information for crop yield predictions in Europe, Int. J. Remote Sens., 25, 53895401, 2004.

Schade, N. H., Macke, A., Sandmann, H., Stick, C.: Enhanced solar global irradiance during cloudy sky conditions, Meteorologische Zeitschrift, 16, 295-303, 2007.

Scheirer, R. and Macke, A.: Cloud inhomogeneity and broadband solar fluxes, J. Geophys. Res., 108, 4599, doi:10.1029/2002JD003321, 2003.

Schmetz, J.: Towards a surface radiation climatology: Retrieval of downward irradiances from satellites, Atmos. Res., 23, 287-321, doi:10.1016/0169-8095(89)90023-9, 1989.

Sengupta, M., Gotseff, P., and Stoffel, T.: Evaluation of Photodiode Thermopile Pyranometers for Photovoltaic Applications, in: 27th European Photovoltaic Solar Energy Conference and Exhibition, Frankfurt, Germany, NREL/CP-5500-56540, available at: http:// www.nrel.gov/docs/fy12osti/56540.pdf (last access: 23 February 2016), 2012.

Stephens, G. L.: Cloud feedbacks in the climate system: a critical review, J. Climate, 18, 237-273, doi:10.1175/JCLI-3243.1, 2005.

van den Hurk, B., Bastiaanssen, W., Pelgrum, H., and van Meijgaard, E.: A new methodology for initialization of soil moisture fields in numerical weather prediction models using METEOSAT and NOAA data, J. Appl. Meteorol., 36, 1271-1283, 1997.

Vuilleumier, L., Hauser, M., Félix, C., Vignola, F., Blanc, P., Kazantzidis, A., and Calpini, B.: Accuracy of ground surface broadband shortwave radiation monitoring, J. Geophys. Res., 119, 13838-13860, doi:10.1002/2014JD022335, 2014.

Wendisch, M., Müller, D., Schell, D., and Heintzenberg, J.: An Airborne Spectral Albedometer with Active Horizontal Stabilization, J. Atmos. Oceanic Technol., 18, 1856-1866, 2001.

Wild, M., Folini, D., Schär, C., Loeb, N., Dutton, E. G., and KönigLanglo, G.: The global energy balance from a surface perspective, Clim. Dynam., 40, 3107-3134, doi:10.1007/s00382-0121569-8, 2013.

WMO: Measurement of radiation, chapter 7, in: Guide to Meteorological Instruments and Methods of Observations, Tech. Rep. WMO-No. 8, World Meteorological Organization, WMO, Geneva, Switzerland, available at: http://www.wmo.int/pages/prog/gcos/documents/ gruanmanuals/CIMO/CIMO_Guide-7th_Edition-2008.pdf (last access: 23 February 2016), 2008. 